\title{
The Effect of Forming Speed on Cold Roll Forming of the Rocket Frame
}

\author{
Fangchao Luan ${ }^{1}$ and Weizhang Wang ${ }^{2, *}$ \\ ${ }^{1}$ Department of Mechanical and Electronic Engineering, Shandong University of Science and \\ Technology, Qingdao, Shandong, China \\ ${ }^{2}$ Department of Mechanical and Electrical Engineering and Vehicle Engineering, Weifang University, \\ Weifang, Shandong, China \\ ${ }^{*}$ Corresponding author
}

Keywords: The rocket frame, Cold roll forming, Finite element analysis.

\begin{abstract}
Aiming at the forming speed of sheet metal, this paper discusses the influence of technological parameters on the quality of the rocket frame. Using 3D software SolidWorks to establish the geometric model of the plate and the upper and lower rolls required in the cold roll forming process, and introduced it into the finite element analysis software ANSYS/LS-DYNA to analyze the change of stress and strain of the plate during the forming process. By comparing the stress-strain nephograms of sheet metal at different forming speeds, it can be seen that with the increasing of forming speed, the maximum Mises stress of the sheet is gradually increasing, and the maximum stain of the sheet is gradually decreasing.
\end{abstract}

\section{Introduction}

During the cold roll forming process, the selection of process parameters plays a crucial role in the molding quality of the final product [1,2]. The deformation and stress of the sheet during the cold roll forming process are very complicated and belong to the nonlinear deformation process [3,4]. At present, many domestic enterprises are relying on experience in the cold roll forming processes. Before actual production, a large number of experiments are often performed, which will generate a large amount of waste products, increase production costs, and waste resources. Aiming at this phenomenon, this paper uses the LS-DYNA analysis module of the finite element analysis software ANSYS to investigate the influence of process parameters on the quality of the frame of the rocket frame by taking the forming speed, forming angle and thickness of the sheet as examples.

\section{The Rocket Frame and Roll Parameters}

In this paper, the simulation analysis of the cold roll forming process of the rocket frame is carried out. Figure 1 is a specification of the rocket frame.

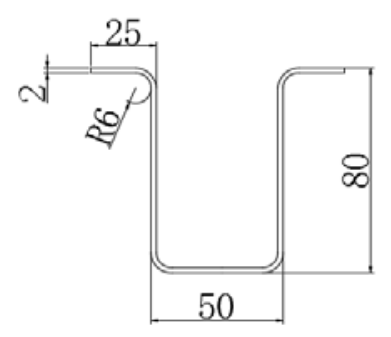

Figure 1. Parameters of the rocket frame

The material of the rocket frame is 7A09, which is a hard aluminum alloy with a tensile strength of $490 \mathrm{MPa}$, a yield strength of $370 \mathrm{MPa}$ [5], and the roll material is Cr12MoV. Table 1 and table 2 are their specific parameters. 
Table 1. Material parameters of rocket frame

\begin{tabular}{|c|c|c|c|c|}
\hline Density $\left[\mathrm{kg} / \mathrm{m}^{3}\right]$ & Elastic Modulus[Pa] & Poisson Ratio[Pa] & Yield Strength[Pa] & Tangent Modulus[Pa] \\
\hline 2700 & $7 \mathrm{e} 10$ & 0.3 & $3.7 \mathrm{e} 8$ & $1.714 \mathrm{e} 9$ \\
\hline
\end{tabular}

Table 2. Material parameters of upper and lower rolls

\begin{tabular}{|c|c|c|}
\hline Density $\left[\mathrm{kg} / \mathrm{m}^{3}\right]$ & Elastic Modulus[Pa] & Poisson Ratio \\
\hline 7850 & $2.06 \mathrm{e} 11$ & 0.28 \\
\hline
\end{tabular}

After analysis, six molding passes were finally selected to complete the molding of the model. The forming angles of the six passes are $10^{\circ}, 25^{\circ}, 45^{\circ}, 65^{\circ}, 80^{\circ}, 90^{\circ}$.

\section{Simulation Analysis Pre-processing}

\section{Model Establishment and Meshing}

This article uses SolidWorks to create 3D model drawings of the plate, the upper rolls and lower rolls, then save the files into $\mathrm{x}$-t format and import them into the LS-DYNA module. SOLID164 solid unit was used in the plate, upper rolls and lower rolls during forming process, which contains 8 nodes, supports the simultaneous application of multiple types of loads, provides a variety of unit algorithms, and accelerates unit calculations by integrating and viscous hourglass control. It is suitable for handling most nonlinear problems. Since the plate, the upper rolls and lower rolls are not very complicated, the sweeping method is used to mesh models. Taking the first pass as an example, the size of the plate unit is controlled to $5 \mathrm{~mm} \times 5 \mathrm{~mm} \times 2 \mathrm{~mm}$, and the number of units obtained after the division is completed is 5760. For the upper and lower rolls, the unit size is controlled to $5 \mathrm{~mm} \times 5 \mathrm{~mm} \times 1 \mathrm{~mm}$, and the division is completed. After getting the upper roller, there are 8692 grid units, and the lower roller has 7791 grid units. Their meshing is shown in the figure 2.

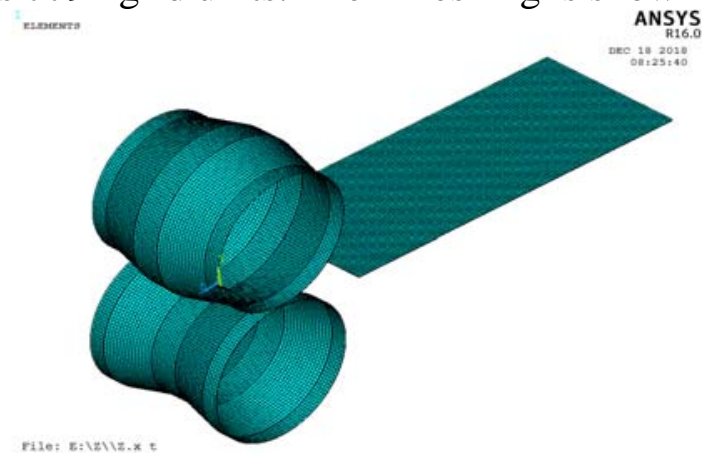

Figure 2. Mesh division of plate, upper roll and lower roll

\section{Contact and Restraint Loads}

The upper surface of the plate is in contact with the outer surface of the upper roll, and the lower surface of the plate is in contact with the outer surface of the lower roll. Therefore, the contact type belongs to surface to surface contact. The cold roll forming design manual shows that the static friction coefficient of the plate and the upper and lower rolls is 0.61 . The dynamic friction coefficient is 0.47 .

For the plate, according to its force characteristics during the cold roll forming process, it is only necessary to limit the movement constraint in the $\mathrm{X}$ direction of the plate to prevent lateral slippage during the simulation process. For the upper and lower rolls, it is necessary to limit the movement constraints in the $\mathrm{X}, \mathrm{Y}$, and $\mathrm{Z}$ directions and the rotation constraints in the $\mathrm{Y}$ and $\mathrm{Z}$ directions, and release the rotation constraint in the $X$ direction. After several simulations and simulations, the forming speed of the plate was finally selected to be $1 \mathrm{~m} / \mathrm{s}$, and the upper and lower rolls were rotated at the corresponding initial speed. 


\section{Simulation Results Analysis}

In this paper, taking the first pass as an example, in the case of ensuring that other parameters are unchanged, the forming speed of the plates is set to $1 \mathrm{~m} / \mathrm{s}, 1.5 \mathrm{~m} / \mathrm{s}, 2 \mathrm{~m} / \mathrm{s}, 2.5 \mathrm{~m} / \mathrm{s}$ and $3 \mathrm{~m} / \mathrm{s}$. Simulation analysis shows that the stress at each speed is shown in figure 3 to figure 7 .

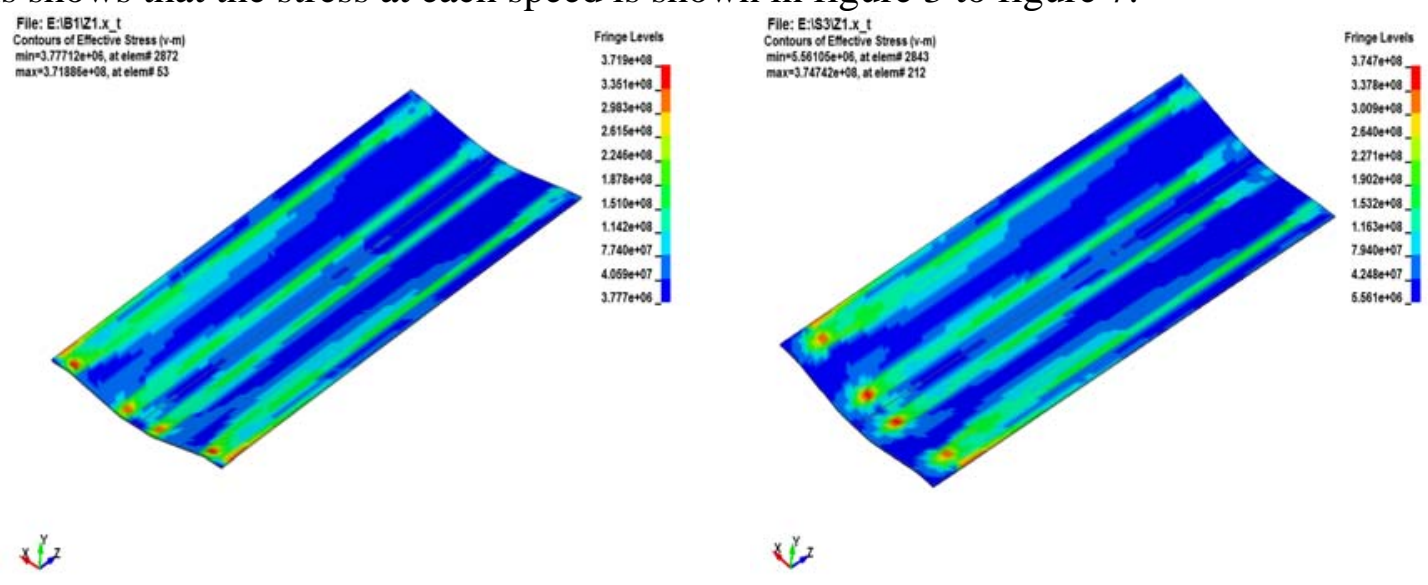

Figure 3. Stress nephogram of $1 \mathrm{~m} / \mathrm{s}$ at velocity

Figure 4. Stress nephogram of $1.5 \mathrm{~m} / \mathrm{s}$ at velocity
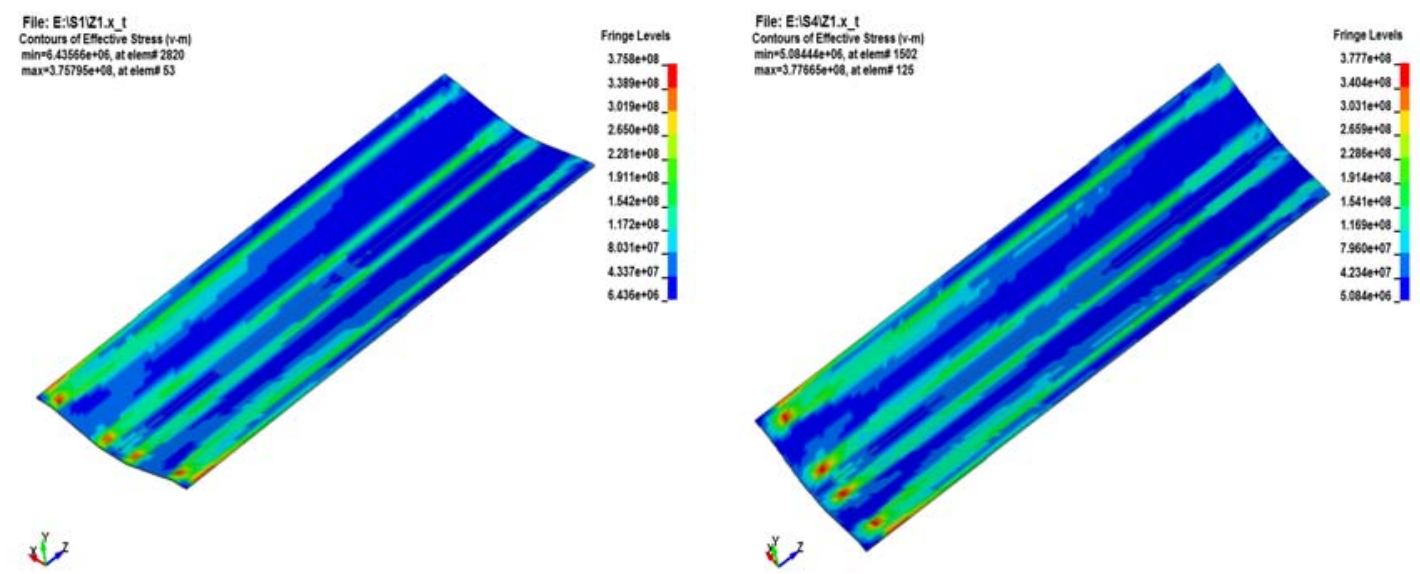

Figure 5. Stress nephogram of $2 \mathrm{~m} / \mathrm{s}$ at velocity

Figure 6. Stress nephogram of $2.5 \mathrm{~m} / \mathrm{s}$ at velocity

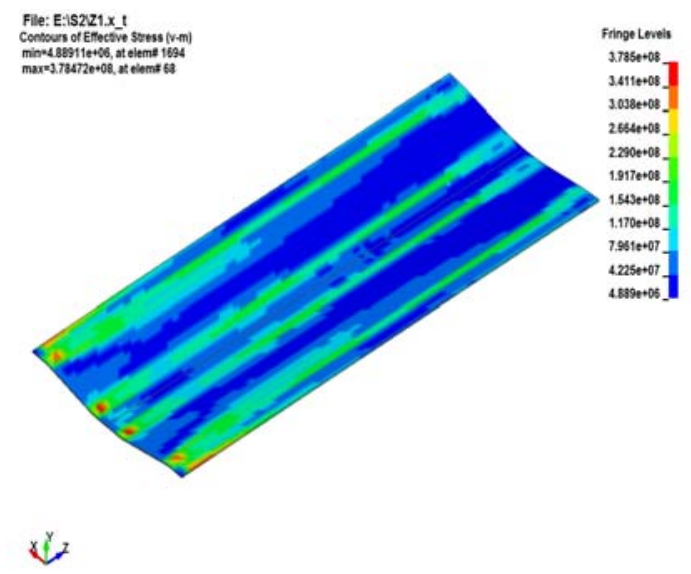

Figure 7. Stress nephogram of $3 \mathrm{~m} / \mathrm{s}$ at velocity

It can be seen from figure 3 to figure 7 that the maximum Mises stress value of the sheet is 371.9 $\mathrm{MPa}$ at a speed of $1 \mathrm{~m} / \mathrm{s}$, the maximum Mises stress value of the sheet is $374.7 \mathrm{MPa}$ a speed of 1.5 $\mathrm{m} / \mathrm{s}$, the maximum Mises stress value of the sheet is $375.8 \mathrm{MPa}$ at a speed of $2 / \mathrm{s}$, the maximum Mises stress value of the sheet is $377.7 \mathrm{MPa}$ when the speed is $2.5 \mathrm{~m} / \mathrm{s}$, and the maximum Mises stress value 
of the sheet is $378.5 \mathrm{MPa}$ when the speed is $3 \mathrm{~m} / \mathrm{s}$. It is concluded that as the forming speed increases during the cold forming process, the maximum Mises stress on the sheet is also increased, and the increased amplitude is not fixed, the increasing slope is different.
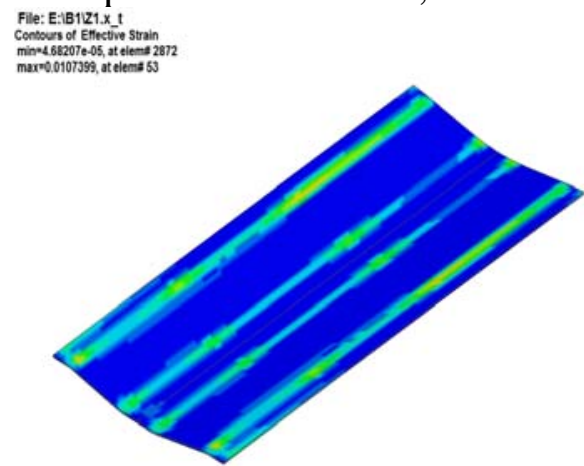

$v^{2}$

Figure 8 . Strain nephogram of $1 \mathrm{~m} / \mathrm{s}$ at velocity

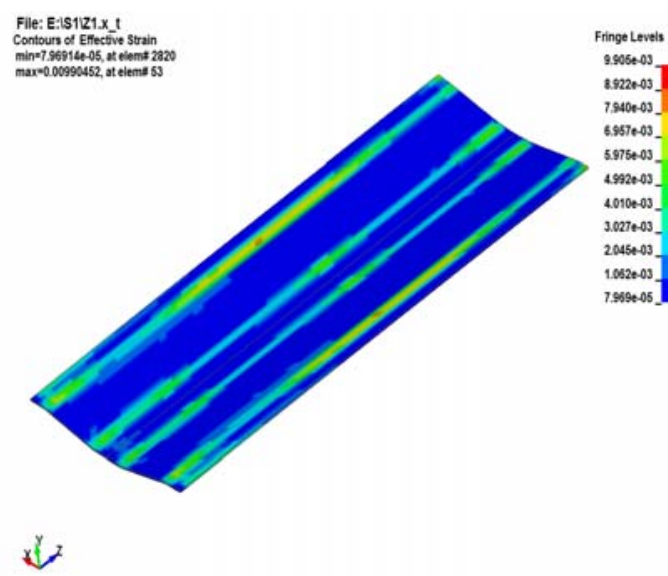

Figure 10. Strain nephogram of $2 \mathrm{~m} / \mathrm{s}$ at velocity

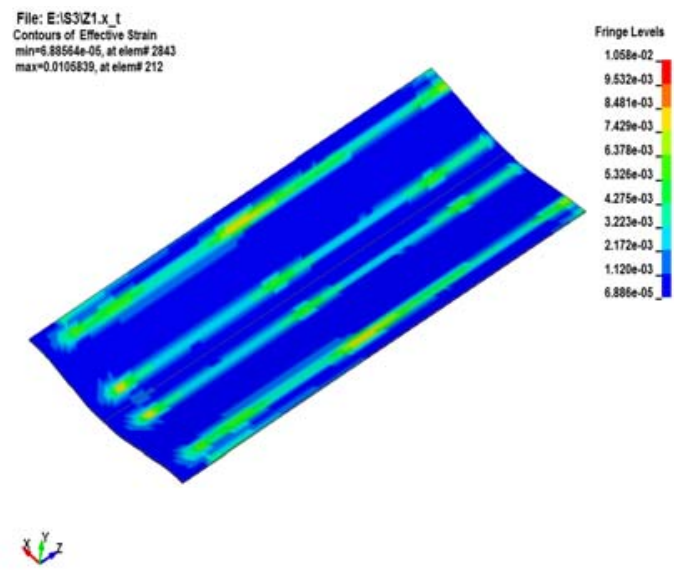

Figure 9. Strain nephogram of $1.5 \mathrm{~m} / \mathrm{s}$ at velocity

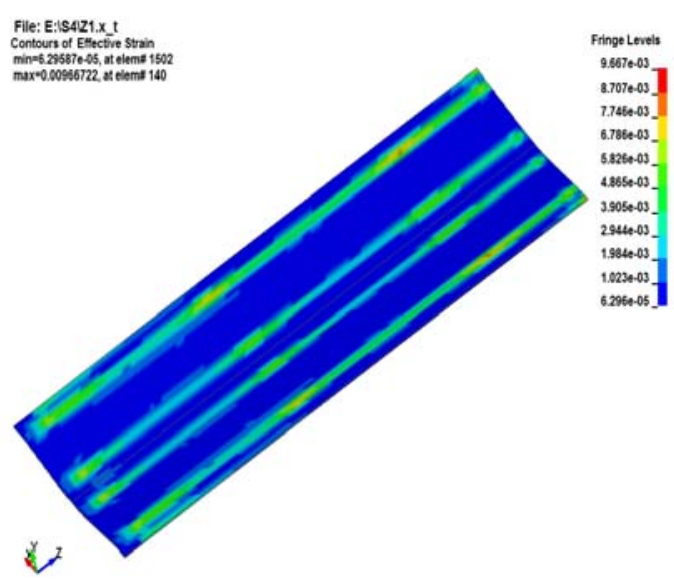

Figure 11. Strain nephogram of $2.5 \mathrm{~m} / \mathrm{s}$ at velocity

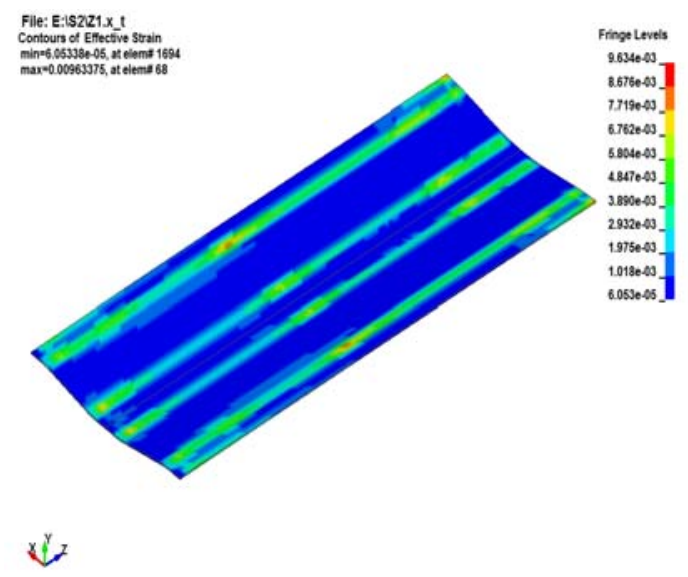

Figure 12. Strain nephogram of $3 \mathrm{~m} / \mathrm{s}$ at velocity

Figure 5.6 to figure 5.10 show the strain of the plates at different speeds. It can be seen from Figure 8 to Figure 12 that the maximum strain value of the sheet is $1.074 \mathrm{e}-2$ at a speed of $1 \mathrm{~m} / \mathrm{s}$, the maximum strain value of the sheet is $1.058 \mathrm{e}-2$ at a speed of $1.5 \mathrm{~m} / \mathrm{s}$, the maximum strain value of the plate is $9.905 \mathrm{e}-3$ when the speed is $2 \mathrm{~m} / \mathrm{s}$, the maximum strain value of the plate is $9.892 \mathrm{e}-3$ when the speed is $2.5 \mathrm{~m} / \mathrm{s}$, and the maximum strain value of the plate is $9.634 \mathrm{e}-3$ when the speed is $3 \mathrm{~m} / \mathrm{s}$. It is 
concluded that as the forming speed increases during the cold forming process, the maximum plasticity of the sheet gradually decreases.

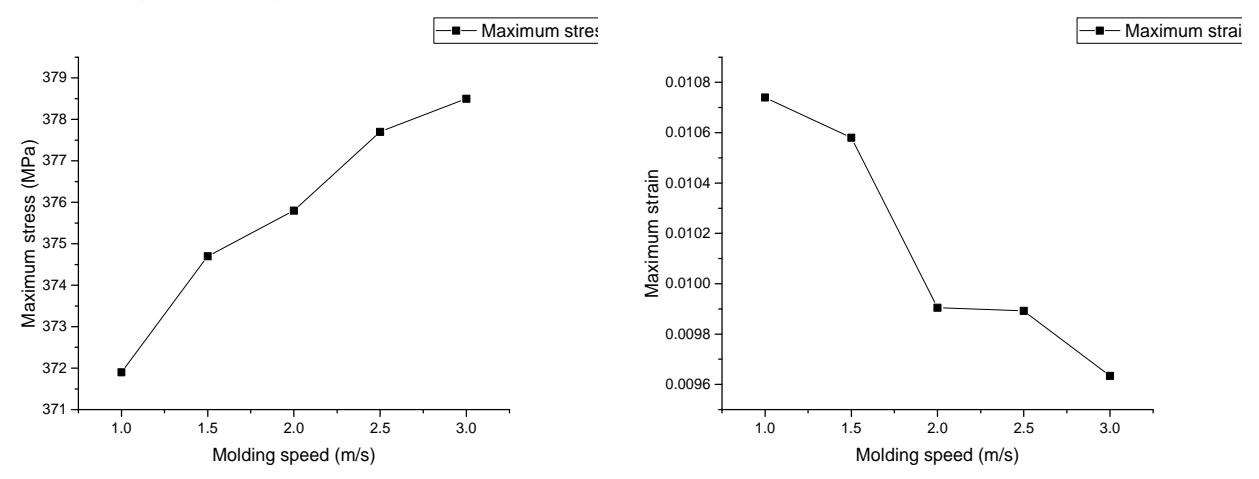

Figure 13. Maximum stress and strain at various forming speeds

The maximum stress and the maximum strain at various forming speeds is as shown in figure 13.After analysis, it can be seen from figure 13 that the forming speed of the sheet has a great influence on the forming result. With the increasing of forming speed, the maximum Mises stress of the sheet is gradually increasing, while the maximum strain tends to decrease gradually.

\section{Summary}

In this paper, the influence of process parameters on the quality of cold-formed products was discussed by changing the forming speed. Through the simulation analysis of different forming speeds, it is found that with the gradual increasing of forming speed, the maximum Mises stress of the sheet is gradually increasing, and the maximum plasticity of the sheet is gradually decreasing. This is the effect of forming speed accelerating sheet metal can not recrystallize in time.

\section{Acknowledgement}

This research was financially supported by Shandong University of Science and Technology and Weifang University.

\section{References}

[1] R. Safdarian, H. Moslemi Naeini, The effects of forming parameters on the cold roll forming of channel section, Thin-Walled Structures, 2015, 92.

[2] B. Shirani Bidabadi, H. Moslemi Naeini, R. Azizi Tafti, S. Mazdak, Experimental investigation of the ovality of holes on pre-notched channel products in the cold roll forming process, Journal of Materials Processing Tech., 2015, 225.

[3] Xiao-bin WANG, Finite element analysis of roll forming process of channel steel based on ANSYS, Electromechanical information, 2011, 18:163-164.

[4] Qin-hai XIE, Research on cold roll forming system of color steel glazed tile based on virtual reality, Harbin: Harbin Institute of Technology, 2015.

[5] Da-xian CHENG, Mechanical design manual, Beking: Chemical Industry Press, 2010. 